\title{
REVISTA
}

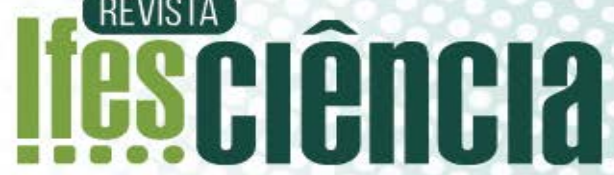

\section{DESEMPENHO DO CAFÉ CONILON CONSORCIADO COM ADUBOS VERDES EM ÁREA DE TRANSIÇÃO AGROECOLÓGICA}

\section{PERFORMANCE OF CONILON COFFEE CONSORTIATED WITH GREEN FERTILIZERS IN AGRICULTURAL TRANSITION AREA}

\author{
${ }^{1}$ Mario Euclides Pechara da Costa Jaeggi \\ ${ }^{1}$ Fábio Cunha Coelho \\ ${ }^{1}$ Israel Martins Pereira \\ ${ }^{1}$ Alex Jusitno Zacarias \\ ${ }^{1}$ Geraldo de Amaral Gravina \\ ${ }^{2}$ Wallace Luis de Lima \\ ${ }^{2}$ André Oliveira Souza \\ ${ }^{3}$ Samuel Ferreira da Silva \\ 3 *Taís Rizzo Moreira \\ ${ }^{3}$ Magno do Carmo Parajara \\ ${ }^{4}$ Lucas Louzada Pereira \\ ${ }^{3}$ Alexandre Rosa dos Santos
}

\begin{abstract}
${ }^{1}$ Universidade Estadual Norte Fluminense. E-mail: mariopechara@hotmail.com; fabiocoelhouenf@gmail.com; israelmartins80@gmail.com; alexjustino12@gmail.com; gravina@uenf.br.

2Instituto Federal do Espírito Santo - Campus Alegre. E-mail: wallace@ifes.edu.br; andreolisouza@gamil.com.

${ }^{3}$ Universidade Federal do Espírito Santo - Campus Alegre. E-mail: samuelfd.silva@yahoo.com.br; taisr.moreira@hotmail.com*; magnocp1@hotmail.com; mundogeomatica@yahoo.com.br. ${ }^{4}$ Instituto Federal do Espírito Santo - Campus Venda Nova do Imigrante. E-mail: lucaslozada@hotmail.com. *Autor de correspondência
\end{abstract}

Artigo submetido em 30/09/2020, aceito em 18/11/2020 e publicado em 23/12/2020.

Resumo: Objetivou-se com este trabalho avaliar as características morfo-agronômicas do cafeeiro conilon submetido a diferentes manejos de espécies de adubos verdes. Foram avaliados cafeeiros contendo as espécies de adubo verde: feijão guandu, feijão de porco, mucuna preta e margaridão mexicano, em ambas as entrelinhas adjacentes (100\%) e apenas na entrelinha superior (50\%), além de um tratamento testemunha (adubação convencional). A unidade experimental constituiu-se de uma planta de cafeeiro, variedade clonal "Incaper 8142" Conilon Vitória variedade 12 V (precoce), com espaçamento de 2,30 x 2,60 m, com cinco repetições. Utilizou-se bordadura de uma planta de cafeeiro entre as unidades experimentais. As varáveis avaliadas foram: comprimento do maior ramo ortotrópico (ALT); diâmetro dos ramos ortotrópicos (DRO); número de ramos plagiotrópicos lançados (NRP); número de nós produtivos dos ramos plagiotrópicos (NP); litros de café colhidos in natura (LTS); quilogramas de café cereja produzidos por planta (kg). O manejo $50 \%$ de feijão guandu foi superior ao convencional para a maioria das características avaliadas, portanto pode ser recomendado, para o primeiro ano de transição agroecológica em lavouras de café conilon.

Palavras-chave: manejo; Coffea canephora; agroecologia. 


\begin{abstract}
The objective of this work was to evaluate the morpho-agronomic characteristics of the conilon coffee tree submitted to different management of green manure species. Coffee trees containing the species of green manure were evaluated: pigeon pea, pork beans, black mucuna and Mexican daisy, in both adjacent lines (100\%) and only upper line (50\%), in addition to a control treatment (conventional fertilization). The experimental unit consisted of a coffee plant, clonal variety "Incaper 8142" Conilon Vitória variety $12 \mathrm{~V}$ (precocious), with a spacing of 2.30 x $2.60 \mathrm{~m}$, with five repetitions. Bordering a coffee plant was used between the experimental units. The variables evaluated were: length of the largest orthotropic branch (ALT); diameter of the orthotropic branches (DRO); number of plagiotropic branches launched (NRP); number of productive nodes in the plagiotropic branches (NP); liters of freshly harvested coffee (LTS); kilograms of cherry coffee produced per plant $(\mathrm{kg})$. The $50 \%$ handling of pigeon pea was superior to the conventional one for most of the evaluated characteristics, therefore it can be recommended, for the first year of agroecology transition in conilon coffee farms.
\end{abstract}

Keywords: management; coffea canephora; agroecology.

\section{INTRODUÇÃO}

Ao longo do ciclo do café, o Brasil alcançou o posto de maior produtor mundial do grão. Produzimos, no ano de 2019, quase o dobro do segundo colocado no ranking, o Vietnã (ICO, 2019). A cafeicultura, vem desempenhando função vital para o desenvolvimento social e econômico de nosso país, garantindo a geração de postos de trabalho, tributos, e contribuindo significativamente para a formação de receita (FASSIO; SILVA, 2007).

Os maiores produtores nacionais de café arábica e conilon são, Minas Gerais e Espírito Santo, respectivamente. Em Minas Gerais, a produção de café arábica está estimada em 31,07 milhões de sacas, o que corresponde a quase $70 \%$ do total de arábica produzido e o Espírito Santo, 9,8 milhões de sacas ou 68,11\% do total de conilon produzido no Brasil (CONAB, 2020). Frente ao exposto tem-se a necessidade de técnicas que auxiliem o produtor no processo produtivo.

Uma rota alternativa ao cultivo de café é a agricultura de base ecológica, que é um ponto de partida para a transição agroecológica e se apresenta como o resultado da utilização de técnicas e métodos que diferem dos convencionais. Na utilização de técnicas agroecológicas, leva-se em consideração aspectos tecnológicos ou agronômicos de produção, e incorpora-se dimensões mais amplas e complexas, que incluem aspectos ambientais, sociais, econômicos e as necessidades nutricionais das plantas (ROSSET et al., 2014).

A demanda nutricional dos cafeeiros pode atingir recomendações entre 120 e 470 kg.ha- ${ }^{-1}$ de N, 120 a 400 kg.ha ${ }^{-1}$ de $\mathrm{K}_{2} \mathrm{O}$ e de 15 a 80 kg.ha ${ }^{-1}$ de $\mathrm{P}_{2} \mathrm{O}_{5}$ (MATIELLO et al., 2005) e o preço dos fertilizantes é um dos itens que mais encarece os custos de produção. Além disso, o Brasil importa $90 \%$ do K, 50\% do $\mathrm{P}$ e $70 \%$ da energia utilizada na fabricação de fertilizantes nitrogenados (MATIELLO et al., 2005.

$\mathrm{Na}$ produção de café, há uma crescente demanda por utilização de insumos de origem biológica e renováveis, cultivos agroecológicos que levem em consideração a harmonização da planta e do meio ao qual ela está inserida. Assim, os estudos sobre processos de ciclagem de nutrientes crescem em importância para o aumento na eficiência das técnicas que visam a melhor nutrição dos cafeeiros. Diante disso, é importante priorizar estudos na área, com intuito de buscar fontes de adubação que visem diminuir os custos e a dependência de insumos industriais para a cafeicultura, sem implicar em perdas significativas de 
produtividade e qualidade (INCAPER, 2016).

A utilização de Fabaceas capazes de realizar simbiose com bactérias fixadoras de nitrogênio atmosférico pode atuar como fonte de N. A adubação verde com Fabaceas concentra outros nutrientes na camada superficial do solo, pela deposição da matéria orgânica, e, além disto, promove melhorias no ambiente radicular dos cafeeiros, tornando-os menos sujeitos a ataques de doenças e mais resistentes a perdas de ramos produtivos (COELHO et al., 2006).

No entanto, apesar dos benefícios potenciais da adubação verde sobre o solo, uma clara correlação negativa entre o acúmulo de matéria seca nas leguminosas, consorciados por três meses, e a produtividade dos cafeeiros é relatada por Paulo et al. (2001, 2006). No Acre, as leguminosas feijão-de-porco, mucuna ou guandu reduziram o crescimento e a primeira produção de cafeeiros quando consorciadas por 5 a 6 meses (BERGO et al., 2006).

Um resultado interessante foi obtido com a consorciação com Flemingia congesta (BERGO et al., 2006). Essa espécie perene, que recebeu dois cortes no período de 12 meses, elevou a produtividade em relação à testemunha, resultando ainda em cafeeiros com tamanho similar ao avaliado no experimento.

Existem ainda relatos do efeito do guandu em elevar a produtividade de cafeeiros adubados em manejo orgânico, quando não aplicada palha de café (MALTA et al., 2007). Contudo, a mesma espécie não influenciou a produtividade em experimento similar (THEODORO; MENDES; GUIMARÃES, 2009). Em ambos os experimentos, conduzidos em Lavras, Minas Gerais, a consorciação foi limitada ao período de três meses, após os quais o guandu foi cortado e colocado sob os cafeeiros.

Outro estudo relata que o sistema agroecológico representa uma abordagem de manejo promissora para a implementação de uma agricultura sustentável. Neste estudo foi demonstrado por meio de análise molecular que o sistema agroecológico mantém uma maior diversidade de Fungos micorrízicos arbusculares em relação aos sistemas convencionais (PRATES JÚNIOR, 2019).

Tendo em vista os diferentes resultados a respeito da agricultura de base ecológica, e sabendo-se que a adubação verde demonstra ser um ponto de partida para transição em sistemas agroecológicos, o objetivo deste trabalho foi avaliar características morfo-agronômicas do cafeeiro conilon submetido a diferentes utilizações de adubos verdes.

\section{MATERIAIS E MÉTODOS}

O experimento foi conduzido no município de Alegre - ES, na latitude $20^{\circ} 45^{\prime} 44^{\prime \prime}$ Sul, longitude $41^{\circ} 27^{\prime} 43^{\prime \prime}$ Oeste e altitude de aproximadamente $134 \mathrm{~m}$. Com estação seca no inverno e verão quente e chuvoso - com temperatura média anual de $22,2^{\circ} \mathrm{C}$, variando de $17^{\circ} \mathrm{C}$ e $29^{\circ} \mathrm{C}$. (PMA, 2020).

O experimento foi realizado em campo, seguindo-se o método de amostragem em lavoura de café préestabelecida, com idade de sete anos, com aproximadamente 1.672 plantas por hectare e instalada em terreno com declividade de $11 \%$.

A unidade experimental constituiuse de uma planta de cafeeiro, variedade clonal "Incaper 8142, Conilon Vitória variedade $12 \mathrm{~V}$ (precoce), com espaçamento de 2,30 x 2,60 metros. Utilizou-se bordadura de pelo menos uma planta de cafeeiro entre as unidades experimentais.

Foram avaliados cafeeiros contendo as espécies de adubo verde: feijão guandu, mucuna preta, feijão de porco, e margaridão mexicano, em ambas as entrelinhas adjacentes (100\%) e apenas na entrelinha superior (50\%), além de um 
tratamento testemunha, sem adubo verde, com adubação convencional.

Antes da instalação do experimento, amostras de solo foram coletadas da camada de $0-20 \mathrm{~cm}$ de profundidade e analisadas seguindo a metodologia recomendada pela Embrapa (1999). Os atributos físicos e químicos do solo antes do plantio dos adubos verdes são apresentados na Tabela 1.

Tabela 1 - Análise química das áreas estudadas antes da montagem do experimento do cafeeiro consorciadas com adubos verdes (feijão de porco, feijão guandu, mucuna preta, margaridão mexicano) e a testemunha.

\begin{tabular}{|c|c|c|c|c|c|}
\hline Determinações & $\begin{array}{l}\text { Feijão } \\
\text { Guandu }\end{array}$ & $\begin{array}{c}\text { Mucuna } \\
\text { Preta }\end{array}$ & $\begin{array}{c}\text { Feijão } \\
\text { de } \\
\text { Porco }\end{array}$ & $\begin{array}{c}\text { Margaridão } \\
\text { Mexicano }\end{array}$ & Testemunha \\
\hline M.O dag/dm ${ }^{3}$ & 1,2 & 1,0 & 1,2 & 1,3 & 1,4 \\
\hline $\mathrm{pH}$ & 5,5 & 5,4 & 5,4 & 5,4 & 5,5 \\
\hline $\mathrm{P} \mathrm{mg} / \mathrm{dm}^{3}$ & 3,4 & 3,7 & 3,2 & 3,4 & 4,2 \\
\hline $\mathrm{K} \mathrm{mg/dm}{ }^{3}$ & 78,0 & 60,0 & 98,0 & 41,0 & 72,0 \\
\hline $\mathrm{Ca} \mathrm{cmol} / \mathrm{dm}^{3}$ & 2,2 & 2,6 & 2,6 & 2,6 & 2,6 \\
\hline $\mathrm{Mg} \mathrm{cmol} / \mathrm{dm}^{3}$ & 0,7 & 0,8 & 0,9 & 0,9 & 0,8 \\
\hline $\mathrm{Al} \mathrm{cmol} / \mathrm{dm}^{3}$ & 0,4 & 0,2 & 0,3 & 0,2 & 0,2 \\
\hline $\mathrm{H}+\mathrm{Al} \mathrm{cmol} / \mathrm{dm}^{3}$ & 5,8 & 5,3 & 5,3 & 5,1 & 5,3 \\
\hline $\mathrm{SB} \mathrm{cmol} / \mathrm{dm}^{3}$ & 3,1 & 3,6 & 3,8 & 3,6 & 3,6 \\
\hline $\mathrm{CTC} \mathrm{cmol} / \mathrm{dm}^{3}$ & 8,9 & 8,9 & 9,1 & 8,7 & 8,9 \\
\hline $\mathrm{V} \%$ & 35,0 & 40,0 & 41,0 & 41,0 & 40,0 \\
\hline \% K CTC & 2,0 & 2,0 & 3,0 & 1,0 & 2,0 \\
\hline$\%$ Ca CTC & 25,0 & 29,0 & 29,0 & 30,0 & 29,0 \\
\hline$\% \mathrm{Mg}$ CTC & 8,0 & 9,0 & 10,0 & 10,0 & 9,0 \\
\hline$\% \mathrm{Al} \mathrm{CTC}$ & 3,9 & 2,7 & 2,9 & 2,4 & 2,0 \\
\hline$\% \mathrm{H}+\mathrm{Al}$ CTC & 65,0 & 60,0 & 59,0 & 59,0 & 60,0 \\
\hline P-rem mg/L & 28,6 & 31,6 & 32,9 & 28,1 & 32,7 \\
\hline S. monóico $\mathrm{mg} / \mathrm{dm}^{3}$ & 28,0 & 30,0 & 20,0 & 26,0 & 20,0 \\
\hline $\mathrm{B} \mathrm{mg} / \mathrm{dm}^{3}$ & 0,4 & 0,5 & 0,6 & 0,5 & 0,6 \\
\hline 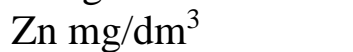 & 0,5 & 0,6 & 0,7 & 0,6 & 1,2 \\
\hline $\mathrm{Mn} \mathrm{mg} / \mathrm{dm}^{3}$ & 15,2 & 12,5 & 17,4 & 13,0 & 16,1 \\
\hline 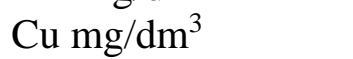 & 0,3 & 0,2 & 0,3 & 0,2 & 0,3 \\
\hline Fe mg/dm ${ }^{3}$ & 32,0 & 37,0 & 36,0 & 28,0 & 34,0 \\
\hline
\end{tabular}

Fonte: elaborado pelos autores.

As leguminosas foram semeadas a aproximadamente $1,30 \mathrm{~m}$ do caule dos cafeeiros em fileira única, em sulco disposto nas entrelinhas dos cafeeiros. Utilizou-se as densidades de semeadura indicadas nas recomendações técnicas de Calegari (1995) para o feijão guandu, mucuna preta e feijão de porco. O plantio do margaridão mexicano foi realizado com a utilização de estacas com comprimento de $20 \mathrm{~cm}$ e espaçadas por $50 \mathrm{~cm}$.

O corte dos adubos verdes foi realizado no período em que o cafeeiro se encontrava em estádio de endurecimento do pergaminho, entre novembro/dezembro. A mucuna preta e o feijão de porco foram cortados rente ao solo, com o auxílio de roçadeira portátil, sendo deixados sobre a superfície do solo. Posteriormente, fez-se novamente a semeadura destas espécies em cada tratamento. O corte do feijão de porco ocorreu aos 75 dias após a semeadura, quando as plantas se encontravam em pleno florescimento. Para mucuna preta o corte foi realizado aos 90 dias após a semeadura, em que as plantas se 
encontravam em estádio vegetativo. Para o feijão guandu a poda foi efetuada quando as plantas atingiram $1,70 \mathrm{~m}$, aos 90 dias após o plantio, período em que a espécie se encontrava em pleno crescimento vegetativo, reduzindo-se a altura para 1,20 $\mathrm{m}$, em relação ao solo (CALEGARI, 1995).

$\mathrm{Na}$ ausência de referências bibliográficas para o manejo do margaridão mexicano, adotou-se o recomendado para o feijão guandu, por apresentarem crescimento vegetativo semelhante.

O tratamento testemunha (adubação convencional) foi adubado em duas épocas: no estádio de grão chumbinho e no início do estádio de endurecimento do pergaminho, em outubro e novembro, respectivamente. A adubação mineral por planta foi composta por $45 \mathrm{~g}$ de ureia, 27,5 g de cloreto de potássio e 35 g de superfosfato simples, em cada uma das épocas, de acordo com as recomendações da análise do solo da área seguindo as recomendações de Prezotti \& Muner (2008).

Após os cortes ou podas dos adubos verdes, o total de matéria fresca produzido em cada tratamento foi pesado e uma amostra de $50 \mathrm{~g}$ foi colocada em estufa com circulação forçada de ar, mantida a temperatura de $65{ }^{\circ} \mathrm{C}$, por 72 horas. Posteriormente, estas amostras foram pesadas obtendo-se o teor de matéria seca de cada espécie de adubo verde. Com estes valores, calculou-se a produção de matéria seca por unidade experimental e a produtividade de matéria seca por hectare (CRUSCIOL et al., 2008).

As características morfoagronômicas avaliadas nos cafeeiros foram:

a) comprimento do maior ramo ortotrópico, foi selecionado o maior ramo ortotrópico e medido a partir de $20 \mathrm{~cm}$ da superfície do solo até seu ápice (m). Esta característica foi nominada como altura da planta (ALT). b) diâmetro dos ramos ortotrópicos (DRO), com medição padronizada na região central do segundo entrenó de cada um dos dois ramos (mm);

c) número de nó produtivos dos ramos plagiotrópicos (NP), obtidos pela contagem direta dos nós nos ramos selecionados;

d) número de ramos plagiotrópicos lançados (NRP), obtido pela contagem direta em dois ramos ortotrópicos por planta;

e) litros de café colhido in natura (LTS), após a colheita do café utilizando um recipiente graduado para mensurar a capacidade em volume colhido por planta.

f) quilogramas de café cereja produzidos por planta (KG) pela pesagem do café após colheita, utilizando balança digital.

As características morfoagronômicas citadas anteriormente, foram avaliadas inicialmente em setembro de 2015 e ao final do experimento em abril de 2016. Com os dados obtidos calculou-se os incrementos destas características.

Os ramos plagiotrópicos selecionados para as medições foram três por planta, sendo estes os maiores entre aqueles que se direcionavam no sentido transversal às entrelinhas dos cafeeiros. As mensurações foram realizadas com paquímetro digital e trena manual. Todas as variáveis foram coletadas no período da colheita.

Utilizando o aplicativo computacional R Core Team (2016), foi realizada a análise descritiva formando gráficos individuais para cada característica avaliada e, posteriormente, foi empregado intervalos de confiança a $5 \%$ de probabilidade.

\section{RESULTADOS E DISCUSSÃO}

No manejo $100 \%$, a mucuna preta foi o adubo verde que mais proporcionou aporte de matéria seca para a adubação verde dos cafeeiros sendo, aproximadamente, o dobro dos fornecidos 
pelo feijão guandu e feijão de porco e o triplo do produzido pelo margaridão mexicano (Tabela 2). No manejo 50\%, a matéria seca produzida pela mucuna preta foi, em média, 1,6 vez maior do que o feijão guandu e o feijão de porco e 3,6 vezes maior que o margaridão mexicano.

Tabela 2 - Estimativa de produção de matéria seca dos adubos verdes cultivados nas entrelinhas das plantas cafeeiras, em manejos $100 \%$ e $50 \%$.

\begin{tabular}{|c|c|c|}
\hline Espécies de adubos verdes & $100 \%$ & $50 \%$ \\
\hline & \multicolumn{2}{|c|}{ Mg ha $^{-1}$} \\
\hline Feijão guandu & 5,9 & 3,0 \\
\hline Mucuna preta & 10,8 & 4,7 \\
\hline Feijão de porco & 5,0 & 2,8 \\
\hline M. mexicano & 2,7 & 1,3 \\
\hline
\end{tabular}

Fonte: elaborado pelos autores.

O feijão guandu, no manejo 50\%, proporcionou acréscimo na altura das plantas de cafeeiro que foi sete $\mathrm{cm}$ a mais do que o proporcionado no manejo $100 \%$, enquanto, os demais adubos não apresentaram diferença entre os manejos (Figura 1).

Figura 1 - Incremento de altura das plantas cafeeiras $(\mathrm{em} \mathrm{cm})$ submetidas a manejo convencional ou com adubos verdes, $100 \%$ corresponde ao adubo verde nas duas linhas adjacentes ao cafeeiro e 50\% (linhas alternadas) com intervalo de confiança calculado com 5\% pelo teste de Student (t).

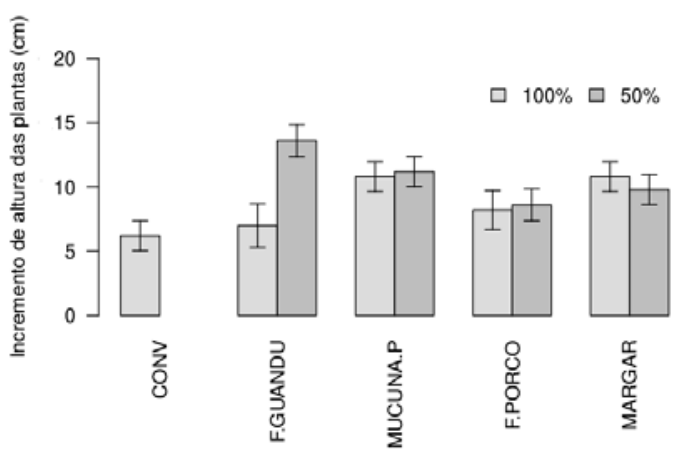

Fonte: elaborada pelos autores.

Em comparação ao manejo convencional, o feijão guandu e o feijão de porco no manejo $50 \%$, proporcionaram acréscimos de 7,4 e $2,4 \mathrm{~cm}$ a mais nas alturas das plantas de café, em relação ao convencional (Figura 1). De forma semelhante, na média dos manejos, a mucuna preta e margaridão mexicano resultou em acréscimo de 5 e $4 \mathrm{~cm}$, a mais em relação ao convencional (Figura 1).

Possivelmente, o sombreamento proporcionado pelo feijão guandu e pelo margaridão mexicano, ambas, plantas de porte elevado, fizeram com que as plantas cafeeiras estiolassem ou, então, o que é mais plausível, a melhor nutrição do cafeeiro, proporcionada pela adubação verde com estas leguminosas, resultou em maior crescimento das plantas, assim como também ocorreu com a mucuna preta e o margaridão mexicano e o feijão de porco no manejo 50\% (Figura 1).

Os resultados encontrados estão de acordo com e Carelli et al. (1999) que observaram efeito de manejos podendo estes gerar competição por luz e reduzir o crescimento em altura das plantas cafeeiras. Suárez de Castro et al. (1961), analisando plantas recém transplantadas a campo, observaram maior crescimento em altura nos ambientes com maior densidade de sombreamento.

Morais et al. (2008) verificaram que o porte elevado do feijão guandu provoca alterações no microclima, devido ao sombreamento, podendo afetar a morfologia e a fisiologia do cafeeiro. Contudo, a magnitude destas alterações depende do tipo, densidade, duração e época em que ocorre o sombreamento, bem como das condições climáticas vigentes, cultivar de cafeeiro, idade da planta, entre outros fatores. Pezzopane et al. (2007) 
avaliaram cafezais em sistema de consórcio com banana prata-anã (Musa ssp.), e constataram que no cultivo consorciado, especialmente nos cafeeiros mais próximos às bananeiras, ocorreram alterações significativas no crescimento vegetativo e no desenvolvimento fenológico das plantas.

Diversos autores, como por exemplo, Paulo et al. (2006), demonstraram em seus trabalhos a importância do manejo adequado dos adubos verdes, para evitar danos às plantas cafeeiras, principalmente, quando o mesmo entra no período de produção. Assim, os fatores, não só ambientais, mas, também, de manejo, podem prejudicar a planta, fazendo com que a altura seja afetada, comprometendo assim o potencial da safra seguinte.

Quanto ao incremento do diâmetro dos ramos ortotrópicos, os manejos não apresentaram diferenças (Figura 2).

Figura 2 - Incremento de diâmetro dos ramos ortotrópicos das plantas cafeeiras

$(\mathrm{em} \mathrm{cm})$ submetidas a manejo convencional ou com adubos verdes, 100\% corresponde ao adubo verde nas duas linhas adjacentes ao cafeeiro e 50\% manejos com (linhas alternadas) com intervalo de confiança calculado com 5\% pelo teste de Student $(\mathrm{t})$.
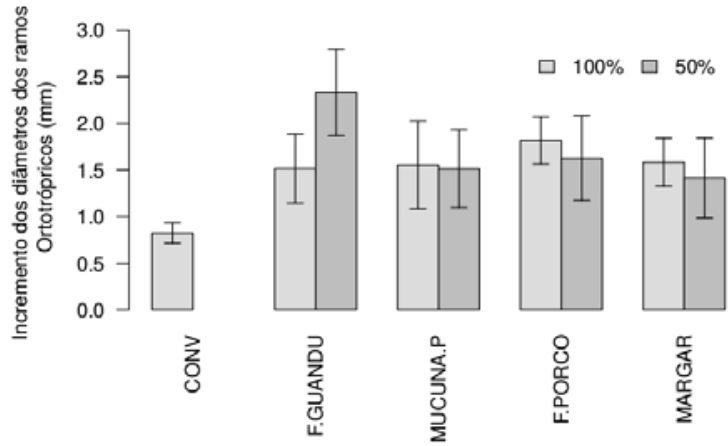

Fonte: elaborado pelos autores.

Em relação ao manejo convencional, foi observado que a média dos manejos do feijão guandu, feijão de porco, mucuna preta e margaridão mexicano proporcionaram acréscimos no diâmetro dos ramos ortotrópicos de 1,10; 0,$90 ; 0,75$ e $0,68 \mathrm{~mm}$ a mais em relação ao convencional (Figura 2).

O incremento de diâmetro do caule foi maior nas plantas adubadas com feijão guandu e feijão de porco, certamente, devido à melhoria na nutrição do cafeeiro proporcionada por estas plantas. Entretanto, estes resultados são parcialmente contrários, aos obtidos por Barrella (2010), que avaliou o consórcio entre café e adubos verdes. Em seu experimento, o feijão guandu não resultou em acréscimo no diâmetro do caule dos cafeeiros, no primeiro ano de avaliação, porém, o feijão de porco sim.

O feijão guandu, no manejo $50 \%$, proporcionou incremento de 4,8 nós produtivos em relação ao manejo $100 \%$, nos demais adubos estudados não houve diferença (Figura 3).

Figura 3 - Incremento de número de nós produtivos das plantas cafeeiras $(\mathrm{em} \mathrm{cm})$ submetidas a manejo convencional ou com adubos verdes, $100 \%$ (adubo verde nas duas linhas adjacentes ao cafeeiro) e 50\%

(linhas alternadas), com intervalo de confiança calculado com $5 \%$ pelo teste de Student (t).
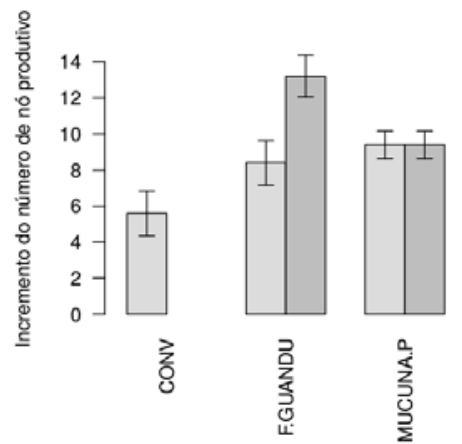

$\square \quad 100 \% \square 50 \%$
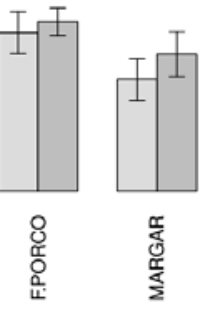

Fonte: elaborado pelos autores.

Avaliando os adubos verdes em relação ao manejo convencional foi observado que o feijão guandu no manejo $100 \%$ e $50 \%$ proporcionaram incrementos de 2,8 e 7,6 nó produtivos nas plantas de café em relação ao convencional. Nas médias dos manejos com mucuna preta e feijão de porco, o incremento foi de 3,7 e 
3,5 nós produtivos em relação ao convencional (Figura 3).

A mucuna preta foi o adubo verde que apresentou a maior produção de matéria seca $\left(10,8 \mathrm{Mg} \mathrm{ha}^{-1}\right.$ no manejo $100 \%$ ) (Tabela 2), isto indica que nem sempre o maior crescimento de um adubo verde é desejável, pois, este resultou em menor número de nós produtivos em relação ao feijão guandu, no manejo $50 \%$, que produziu $3 \mathrm{Mg} \mathrm{ha}^{-1}$ de matéria seca. Isto demonstra que a menor produção de massa seca foi satisfatória.

Um dos mais importantes componentes da produção é o número de nós formados (nós produtivos), assim como o número de frutos presentes em cada nó, que são diretamente afetados pela intensidade de radiação solar e influenciam diretamente a produção.

Campanha et al. (2004) observaram maior número de nó nos ramos plagiotrópicos em planta cafeeira consorciada em relação a plantas a pleno sol. Por outro lado, Morais (2003) constatou que o número de nó por ramo, além do número de nó produtivos, aumentaram significativamente nos cafeeiros que sofreram maior disponibilidade de irradiância.

Ricci et al. (2007) concluíram que o consórcio com adubos verdes reduz o diâmetro dos cafeeiros, o número de ramos produtivos e de nó por ramos, mas aumenta a área foliar e o peso dos grãos, permitindo a obtenção de produção semelhante ao cultivo a pleno sol.

$\mathrm{Na}$ avaliação do incremento do número de ramos plagiotrópicos, observase que não houve diferença entre os manejos estudados nos adubos verdes (Figura 4).

Entretanto, avaliando os adubos verdes em relação ao manejo convencional foi observado que nas médias dos manejos dos adubos feijão guandu e feijão de porco o incremento foi de 3,1 e 3,9 ramos plagiotrópicos a mais em relação ao convencional (Figura 4).
Figura 4 - Incremento de número de ramos plagiotrópicos das plantas cafeeiras (em $\mathrm{cm}$ ) submetidas a manejo convencional ou com adubos verdes, $100 \%$ (adubo verde nas duas linhas adjacentes ao cafeeiro) e 50\% (linhas alternadas), com intervalo de confiança calculado com 5\% pelo teste de Student (t).

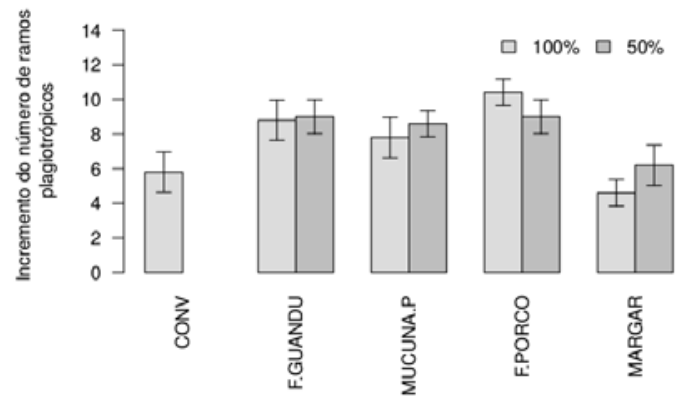

Fonte: elaborado pelos autores.

Entretanto, no manejo de 50\%, a mucuna preta resultou em acréscimo de 2,7 ramos plagiotrópicos em relação ao convencional (Figura 4). Constatou-se que as plantas cafeeiras que eram adubadas com adubos verdes promoveram baixas perdas dos ramos plagiotrópicos. Assim a associação do adubo verde, feijão guandu parece ter conferido melhor condição para nutrição nitrogenada; o que não ocorreu com os demais adubos avaliados e, como consequência, houve perdas de números de ramos plagiotrópicos.

Plantas de cafeeiros com maior radiação luminosa ou cultivadas a pleno sol podem proporcionar maior número de nós nos ramos plagiotrópicos primários e um maior comprimento dos internódios desses ramos (LUNZ, 2006)

Morais (2003) não observou diferença significativa no número de ramos plagiotrópicos de plantas a pleno sol e sombreado com feijão guandu; no entanto, estes últimos proporcionaram maior percentual de ramos com frutos.

O aumento do número de ramos plagiotrópicos pode ser considerado como um aumento do potencial produtivo do cafeeiro, uma vez que ocorra aumento no 
número de nós, local onde se originam as gemas laterais com capacidade produtiva. Contudo, o lançamento excessivo de ramificações secundárias e terciárias pode prejudicar a safra seguinte, pois pode estar ocorrendo uma grande diferenciação de gemas vegetativas em detrimento das reprodutivas (MORAIS, 2003).

$\mathrm{Na}$ avaliação da produtividade em litros de café cereja por planta, verificou-se que não ocorreu diferença entre os manejos 50 e $100 \%$ nos adubos verdes avaliados (Figura 5). Da mesma forma, na comparação entre o manejo convencional e os adubos verdes, não foi observado diferença de produtividade em litros por planta (Figura 5).

Figura 5 - Produtividade de café cereja em plantas cafeeiras $(\mathrm{em} \mathrm{cm})$ submetidas a manejo convencional e com adubos verdes, $100 \%$ (adubo verde nas duas linhas adjacentes ao cafeeiro) e 50\% (linhas alternadas), com intervalo de confiança calculado com 5\% pelo teste de Student (t).
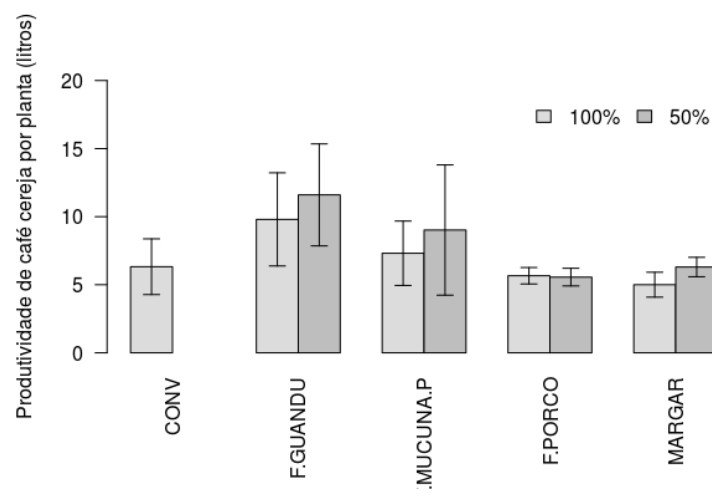

Fonte: elaborado pelos autores.

Pezzopane et al. (2011), trabalhando com o consórcio macadâmia e café, constataram que a presença da cultura de sombreamento altera o microclima. Cultivos de cafés em sistema de consórcio com Musa AAB e Grevillea robusta, registram atenuação de até $27 \%$ da irradiância, fato que não se mostrou relevante para alterações no crescimento e desenvolvimento dos cafeeiros. RodríguezLópez et al. (2014) afirmaram que as diferenças na disponibilidade de radiação e alterações sazonais podem causar alterações na estrutura e função das folhas do cafeeiro, como alterações fisiológicas no crescimento e desenvolvimento da planta, podendo até promover melhor desempenho fotossintético, mantendo a produtividade.

$\mathrm{Na}$ avaliação da produtividade de café cereja por planta expresso em kg não se verificou diferença entre os manejos dos adubos verdes (Figura 6).

Figura 6 - Produtividade expresso em quilograma de café cereja por planta em cafeeiros $(\mathrm{em} \mathrm{cm})$ submetidas a manejo convencional e com adubos verdes, $100 \%$ (adubo verde nas duas linhas adjacentes ao cafeeiro) e 50\% (linhas alternadas), com intervalo de confiança calculado com 5\% pelo teste de Student (t).

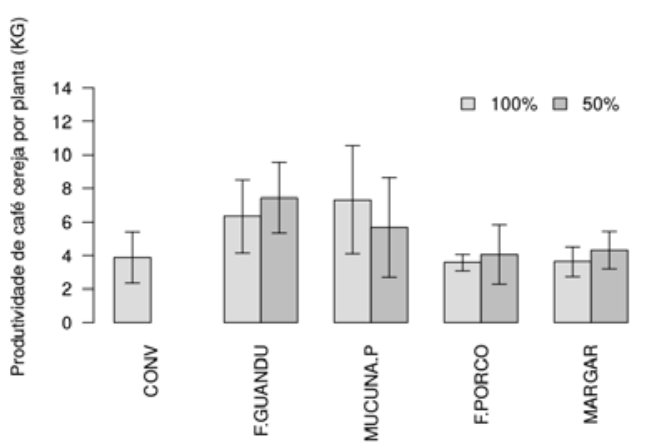

Fonte: elaborado pelos autores.

Entretanto, em relação ao manejo convencional, foi observado que o feijão guandu, no manejo $50 \%$, proporcionou incremento de $3,57 \mathrm{~kg}$ por planta de café (Figura 6), o que corresponde a $5.970 \mathrm{~kg}$ ha $^{-1}$ já que a população de plantas foi de 1.672 plantas de café por hectare. Por outro lado, os demais adubos verdes não proporcionaram incrementos significativos em relação ao manejo convencional (Figura 6)

$\mathrm{O}$ incremento na produtividade proporcionado pelo feijão guandu no manejo 50\% (Figura 6), certamente está associado aos incrementos em altura da planta (Figura 1) e número de nós produtivos (Figura 3). 
Vários estudos sobre a adubação do cafeeiro confirmaram a possibilidade de substituição parcial das adubações químicas por outras fontes de adubos, sejam elas orgânica ou verde, desde que se tenha o equilíbrio necessário da fertilidade do solo e do estado nutricional das lavouras cafeeiras (BARROS et al., 1999). Nesse contexto, Furtini Neto et al. (1995), relatam que a adubação orgânica é capaz de suprir as necessidades das lavouras somente até os dois primeiros anos após o plantio. A partir desse período, torna-se necessário à complementação com fertilizantes químicos. Segundo Paulo et al. (2006), estudando espécies de leguminosas nas entrelinhas do cafeeiro, concluíram que o uso durante sete anos consecutivos dos adubos verdes Crotalária espectabilis, Crotalaria juncea, mucuna anã ou da soja não diminuiu a produtividade e não interferiu no desenvolvimento do cafeeiro.

Alguns autores relatam que 0 processo de conversão é uma etapa delicada, na qual há um desequilíbrio nutricional que reflete na produtividade e desenvolvimento da lavoura cafeeira. Assis \& Romeiro (2004), estudando sistemas de produção de café orgânico em propriedades de agricultores familiares, relataram que a produtividade antes da transição era de 13 a 28 sacas ha ${ }^{-1}$; durante o período de conversão, foi reduzida para 10 a 18 sacas ha $^{-1}$ e, finalmente, após o período de conversão, a produtividade aumentou para um patamar entre 27 a 38 sacas ha-1. Darolt (2000), afirma que a conversão para a agricultura orgânica ou agroecologia, apesar de ser uma etapa delicada nos primeiros anos, proporciona, com o passar do tempo, um impacto favorável na sustentabilidade em suas diferentes dimensões.

Vale ressaltar que o manejo $50 \%$ de feijão guandu foi superior ao convencional para as características altura da planta e número de nós produtivos. Quanto aos demais adubos verdes vale considerar que, algumas espécies liberam os nutrientes de maneira lenta, possuindo taxas de decomposição diferenciadas, o que dificulta muitas das vezes a comparação do efeito destes com os dos fertilizantes químicos tradicionais, que estão prontamente disponíveis para as plantas.

\section{CONCLUSÕES}

O manejo 50\% de feijão guandu foi superior ao convencional para a maioria das características avaliadas (altura das plantas, diâmetro do ramo ortotrópico e, número de folhas, número de nós produtivos, número de ramos plagiotrópicos e produtividade em quilogramas de café cereja por planta), portanto pode ser recomendado, para o primeiro ano de transição. Ressalta-se que esta recomendação é especificamente para a variedade clonal "Incaper 8142" Conilon Vitória clone $12 \mathrm{~V}$ (precoce).

Assim, em relação ao manejo convencional, foi observado que o feijão guandu, no manejo 50\%, proporcionou incremento de 3,57 kg de grãos cereja por planta de café, o que corresponde a 5.970 $\mathrm{kg} \mathrm{ha}^{-1}$ já que a população de plantas foi de 1.672 plantas de café por hectare. Por outro lado, os demais adubos verdes não proporcionaram incrementos significativos em relação ao manejo convencional.

\section{REFERÊNCIAS}

ASSIS, R. L.; ROMEIRO, A. R. Análise do processo de conversão de sistemas de produção de café convencional para orgânico: um estudo de caso. Cadernos de Ciência \& Tecnologia, v. 21, p. 143-168, 2004.

BARRELLA, T. P. Manejo de espécies de leguminosas em cafezal sob cultivo orgânico. 2010. 95 f. Tese (Doutorado em Fitotecnia) - Universidade Federal de Viçosa - UFV, Viçosa, 2010.

BERGO, L. C. et al. Avaliação de espécies leguminosas na formação de cafezais no segmento da agricultura familiar no Acre. 
Acta Amazônica, Manaus, v. 36, n. 1, p. 19-24, 2006.

BARROS, U. V. et al. Doses e modo de aplicação da palha de café e esterco de gado associado ao adubo químico, na formação e produção do cafeeiro na zona da mata. In: CONGRESSO BRASILEIRO DE PESQUISAS CAFEEIRAS, 25., 1999, Franca, SP. Anais... Franca, SP: MAPA/ PROCAFÉ, 1999, p. 35-35.

CALEGARI, A. Leguminosas de verão para adubação verde no Paraná.

Londrina: Instituto Agronômico do Paraná, 117 p. (Circular, 80), 1995.

CAMPANHA, M. M; SANTOS, R. H. S.; FREITAS, G.B. Growth and yield of coffee plants in agroforestry and monoculture systems in Minas Gerais, Brazil. Agroforestry Systems, v.63, p.7582, 2004.

CARELLI, M. L. C. et al. Carbon isotope discrimination and gas exchange in Coffea species grown under different irradiance regimes. Revista Brasileira de Fisiologia Vegetal, Brasília, v. 11, p. 63-68, 1999.

Companhia Nacional de Abastecimento (CONAB). Acompanhamento da safra brasileira. Companhia Nacional de Abastecimento. Brasília - DF, 2020.

COELHO, R. A. et al. Efeito de leguminosas arbóreas na nutrição nitrogenada do cafeeiro (Coffea canephora Pierre ex Froehn) consorciado com bananeira em sistema orgânico de produção. Coffee Science, Lavras, v. 1, n. 1. p. 21-27, 2006.

CRUSCIOL, C. A. C. et al. Taxas de decomposição e de liberação de macronutrientes da palhada de aveia preta em plantio direto. Bragantia, Campinas, v. 67, p. 481-489, 2008.
DAROLT, M. R. As dimensões da sustentabilidade: um estudo da agricultura orgânica na região metropolitana de Curitiba-PR. 2000. 310 f. Tese (Doutorado em Meio Ambiente e Desenvolvimento) Universidade Federal do Paraná-UFPR, Curitiba, 2000.

Empresa Brasileira Pesquisa Agro Pecuária (EMBRAPA). Centro Nacional de Pesquisa de Solos. Sistema Brasileiro de Classificação de Solos. Brasília: Embrapa Produção da Informação; Rio de Janeiro: Embrapa Solos, 412p. 1999.

International Coffee Organization (ICO). Trade Statistics Tables. Disponível em: $<$ http://www.ico.org/new_historical.asp?se ction=Statistics $>$. Acesso em: 23/05/2020.

Instituto capixaba de pesquisa, assistência técnica e extensão rural (INCAPER). “Acesso à informação,"’ Disponível em: $<$ https://incaper.es.gov.br/>. Acesso em: 23/05/2020.

FASSIO, L. H.; SILVA, A. E. S. DA. Importância econômica e social do café conilon. Vitória: Café Conilon, 14p. 2007.

FURTINI NETO, A. E.; CURI, N.; GUIMARÃES, P. T. G. Fontes de matéria orgânica e fertilização química na formação e produção de cafeeiro (Coffea arabica L.) em latossolo da região do cerrado. Ciência e Prática, Lavras, v. 19, p. 265-271, 1995.

LUNZ, A.M.P. Crescimento e produtividade do cafeeiro sombreado e a pleno sol. 2006. 94 f. Tese (Doutorado em Agronomia) - Escola Superior de Agricultura Luiz de Queiroz - ESALQ, Piracicaba -SP, 2006.

MATIELLO, J. B. et al. Cultura do café do Brasil: novo manual de recomendação. Brasília: MAPA; Fundação Procafé, 434 p., 2005. 
MALTA, M. R. et al. Produtividade de lavouras cafeeiras em conversão para o sistema de produção orgânico. Coffee Science, Lavras, v. 2, n. 2, p. 183-191, 2007.

MORAIS, H. Efeito do sombreamento de cafeeiros (Coffea arabica L.) com guandu (Cajanus cajan (L) Millsp.) no Norte do Paraná. 2003. 118 f. Dissertação (Mestrado em Agronomia) - Universidade Estadual de Londrina - USL, Londrina- PR, 2003.

MORAIS, H. et al. Floral buds development, flowering, photosynthesis and yield of coffee plants under shading conditions. Pesquisa Agropecuária Brasileira, v.43, p.465-472, 2008.

PAULO, E. M. et al. Produtividade do cafeeiro Mundo Novo enxertado e submetido à adubação verde antes e após recepa da lavoura. Bragantia, Campinas, v. 65, n. 1, p. 115-120, 2006.

PAULO, E. M. et al. Produtividade do café apoatã em consórcio com leguminosas na região da Alta Paulista. Bragantia, Campinas, v.60, n.3, p.195-199, 2001.

PEZZOPANE, J. R. M. et al. Alterações microclimáticas em cultivo de café conilon arborizado com coqueiro anão-verde.

Revista Ciência Agronômica, Campinas, v. 42, p. 865-871, 2011.

PEZZOPANE, J. R. M.; PEDRO JÚNIOR, M. J.; GALLO, P. B. Caracterização microclimática em cultivo consorciado café/banana. Revista Brasileira de Engenharia Agrícola e Ambiental (Online), v. 11, n. 03, p. 256-264, 2007.

PRATES JÚNIOR, P. et al.

Agroecological coffee management increases arbuscular mycorrhizal fungi diversity. Plos One. v. 14, n. 1, 2019.

PREFEITURA MUNICIPAL DE ALEGRE - PMA. Características
Geográficas.http://alegre.es.gov.br/site/ind ex.php/acidade/historia/caracteristicasgeog raficas Acesso em: 13 de setembro de 2020.

PREZOTTI, L. C.; MUNER, L. H. Manual de recomendação de calagem e adubação para o Estado do Espírito Santo. $5^{\text {a }}$ aproximação. SEEA/INCAPER, p.115125, 2008.

R Core Team. R: A language and environment for statistical computing. $\mathrm{R}$ Foundation for Statistical Computing, Vienna, Austria. URL https://www.Rproject.org/, 2016.

RICCI, M. S. F.; COSTA, J. R.; SANTOS, V. L. S. Ocorrência de seca de ramos em cafeeiros cultivados no sistema orgânico em diferentes espaçamentos de plantio. Seropédica: Embrapa Agrobiologia. (Documentos, 244), 2007.

RODRÍGUEZ-LÓPEZ, N. F. et al. Morphological and physiological acclimations of coffee seedlings to growth over a range of fixed or changing light supplies. Environmental and Experimental Botany, Paris, v. 102, p. 110, 2014.

ROSSET, J.S. et al. Agricultura Convencional versus Sistemas Agroecológicos: Modelos, Impactos, Avaliação da Qualidade e Perspectivas. Scientia Agraria Paranaensis v. 13, n. 1, p. 80-94, 2014.

SUÁREZ DE CASTRO, F. et al. Efecto del sombrío en los primeros años de vida de un cafetal. Café, Turrialba, v. 3, p. 81102, 1961.

THEODORO, V. C. A.; MENDES, A. N. G.; GUIMARÃES, R. J. Resposta de lavouras cafeeiras em transição agroecológica a diferentes manejos do solo. Coffee Science, Lavras, v. 4, n. 1, p. 56-66, 2009. 